Check for updates

Cite this: RSC Adv., 2017, 7, 19639

\title{
Abnormal adsorption and desorption behavior of pharmaceutical drugs on polystyrene microspheres $\uparrow$
}

\author{
Teng Wang, $\stackrel{+}{+}^{\mathrm{a}}$ Yajun Zheng, $\stackrel{+}{\mathrm{t}}^{\mathrm{a}}$ Xiaoting Wang, ${ }^{\mathrm{a}}$ Qiang Wang, ${ }^{\star \mathrm{b}}$ Congyu Ke, ${ }^{\mathrm{a}}$ \\ Daniel E. Austin, ${ }^{\star c}$ Xiaoxiao Han ${ }^{a}$ and Zhiping Zhang $\mathbb{D D}^{* a}$
}

\begin{abstract}
Herein we report an abnormal adsorption and desorption behavior where a stronger adsorption interaction between polystyrene particles and pharmaceutical drugs results in preferable desorption behavior. This behavior is contrary to the conventional view, in which a weaker adsorption interaction would lead to a more favorable desorption behavior of target molecules at solid surfaces. Different from other materials, numerous experimental results from a combination of mass spectrometry and infrared spectroscopy indicated quantitatively that the adsorption and desorption behavior of pharmaceutical drugs on polystyrene were independent of drug structure and solvent, while the intermolecular hydrogen bond interaction between polystyrene and the drug played a critical role in determining the adsorption and desorption behavior.
\end{abstract}

Received 10th February 2017

Accepted 28th March 2017

DOI: 10.1039/c7ra01693j

rsc.li/rsc-advances

represents a powerful substrate that allows high efficiency treatment of various compounds in complex matrices, a complete analysis of its surface interactions is essential to further understand its performance and to develop improved materials. The characterization of molecular interactions at PS surfaces has involved X-ray photoelectron spectroscopy (XPS), ${ }^{42}$ Fourier transform infrared spectroscopy (FTIR), ${ }^{46}$ reflection fluorescence (RF), ${ }^{18}$ solid-state NMR, ${ }^{47}$ electrophoresis,${ }^{48}$ chromatography, ${ }^{49}$ laser Doppler velocimetry (LDV) ${ }^{41}$ enzyme-linked immunosorbent assay (ELISA), ${ }^{50}$ dynamic light scattering (DLS), ${ }^{43}$ second harmonic generation (SHG), ${ }^{51}$ and titration calorimetry. ${ }^{52}$ However, these techniques are essentially limited to exploring the molecular interaction modes at PS surfaces such as electrostatic interactions ${ }^{43}$ and hydrophobic interactions, ${ }^{53}$ and study the desorption behaviors of analytes on PS substrates. ${ }^{30,32,33,49,54-59}$ For the purpose of fully understanding the interactions between PS and adsorbed molecules, the adsorption and desorption of various compounds to the surfaces of PS particles have been widely analyzed, ${ }^{60-64}$ but attention has been focused mainly on the reversible and irreversible adsorption mechanisms ${ }^{61-63}$ or the effect of experimental parameters on adsorption interaction or performance. ${ }^{60,64}$ There is little available quantitative experimental data on the correlation between adsorption and desorption behaviors of various analytes on PS substrates from different sources, which restricts greatly the understanding and interpretation of different molecular interactions on PS supports even composed of the same matrix. ${ }^{33}$ In view of this fact, in the current study, we illustrated the adsorption and desorption behaviors of several pharmaceutical drugs due to their

\footnotetext{
${ }^{a}$ School of Chemistry and Chemical Engineering, Xi'an Shiyou University, Xi'an 710065, China. E-mail: zhangzp0304@gmail.com

${ }^{b}$ School of Chemistry and Molecular Engineering, Nanjing Tech University, Nanjing 211816, China. E-mail: wangqiang@njtech.edu.cn

'Department of Chemistry and Biochemistry, Brigham Young University, Provo, Utah 84602, USA.E-mail: austin@chem.byu.edu

$\dagger$ Electronic supplementary information (ESI) available: Mass spectra, text, and figures giving experimental details. See DOI: 10.1039/c7ra01693j

$\$$ These authors contributed equally to this work.
} 
significance in clinic applications, ${ }^{65,66}$ on the surfaces of a series of PS microspheres prepared via dispersion polymerization of styrene $^{67,68}$ in ethanol/water system. The effects of experimental conditions on the adsorption and desorption capacities of the resulting PS particles have been explored quantitatively using paper spray mass spectrometry owing to its highly simplified procedures and high specificity, sensitivity and precision. ${ }^{69}$ For example, the desorption experiments were carried out by first depositing $2 \mu \mathrm{L}$ of sample solution containing studied drugs on a small PS coated paper triangle. After drying, $25 \mu \mathrm{L}$ methanol and $3.5 \mathrm{kV}$ DC voltage were subsequently applied on the paper substrate for paper spray. The desorption behaviors of studied drugs on PS particles were quantitatively evaluated by the corresponding peak intensity in the obtained mass spectra. The results revealed for the first time that a stronger adsorption interaction between studied drugs and PS surfaces led to a more favorable desorption behavior.

A series of PS microspheres was first prepared according to the reported dispersion polymerization of styrene ${ }^{67,68}$ in ethanol/water using benzoyl peroxide (BPO) as the initiator and poly( $N$-vinylpyrrolidone) (PVP) as a steric stabilizer. With variation in the reaction parameters such as the concentrations of styrene, BPO or PVP, PS particles with adjustable diameters ranging from 1.0 to $16 \mu \mathrm{m}$ can be synthesized. Only our effort on PS prepared from varying the concentration of styrene is reported in detail here, however. Fig. 1a and b demonstrates the typical scanning electron microscope (SEM) images of PS achieved by reaction of $5 \mathrm{~mL}$ styrene and $1.0 \mathrm{~g}$ BPO in the presence of $1.0 \mathrm{~g}$ PVP using $80 \mathrm{~mL}$ ethanol as solvent, and uniform microspheres with diameters of around $2.0 \mu \mathrm{m}$ were obtained. The FT-IR spectrum (Fig. S1 $\dagger$ ) shows that the sample is a typical PS with characteristics of $\mathrm{C}-\mathrm{H}$ stretching modes for monosubstituted phenyl rings (bands at 3060 and $3026 \mathrm{~cm}^{-1}$ ), C-H stretching modes for the $\mathrm{CH}$ and $\mathrm{CH}_{2}$ groups on the alkyl chain of the polymer (bands at 2924 and $2849 \mathrm{~cm}^{-1}$ ), C-C stretching modes for phenyl rings (bands at 1601, 1493 and 1452 $\left.\mathrm{cm}^{-1}\right)^{70,71}$ To enable on-line desorption experiments of studied drugs at PS surfaces, we coated as-synthesized PS particles onto filter paper (Fig. 1c and d) through a vacuum filtration approach developed in our lab. ${ }^{72,73}$ Note that the nearly monodisperse PS particles form a dense layer on the filter paper. This paperbased substrate is easy to fabricate, and can then be used for paper spray mass spectrometry (MS ${ }^{69}$ experiments to probe the adsorption/desorption behavior. The experimental workflow consists of three steps: (i) fabrication of paper substrate; (ii) deposition of sample solution on PS coated paper; (iii) MS analysis. For example, to evaluate the desorption performance of verapamil from PS coated paper, $2 \mu \mathrm{L}$ of methanol solution containing $1 \mu \mathrm{g} \mathrm{mL} \mathrm{m}^{-1}$ verapamil was spotted on the PS coated paper triangle with around $11 \mathrm{~mm}$ height and $9.5 \mathrm{~mm}$ base width, and the diameter of the wetted spot was about $7.0 \mathrm{~mm}$ (Fig. S2a †). After drying in air for around $4 \mathrm{~h}, 25 \mu \mathrm{L}$ of a methanol solution spiked with $10 \mathrm{ng} \mathrm{mL}^{-1} \mathrm{D}_{6}$-verapamil (internal standard) was applied at the paper surface followed immediately by application of the high voltage needed for paper spray. The $\mathrm{D}_{6}$-verapamil did not have enough time to adsorb thoroughly to the PS prior to paper spray analysis due to the floating
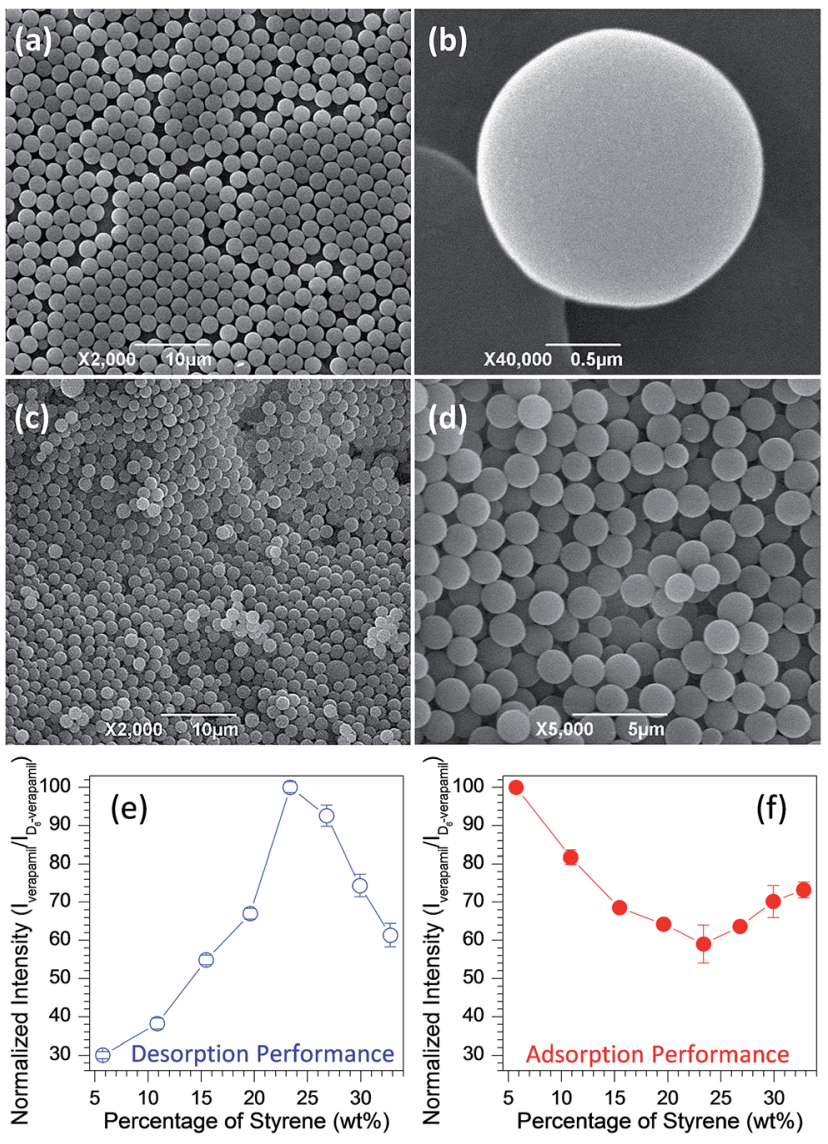

Fig. 1 (a) and (b) SEM images of spherical PS obtained by reaction of 5 $\mathrm{mL}$ styrene and $1.0 \mathrm{~g} \mathrm{BPO}$ in the presence of $1.0 \mathrm{~g}$ PVP by using $80 \mathrm{~mL}$ ethanol as solvent: (a) panoramic morphologies and (b) individual sphere; (c) and (d) SEM images of the surface structure of PS coated paper substrate; (c) as-prepared PS coated paper and (d) close-up image of typical surface structure; (e) desorption behavior of verapamil from PS coated paper substrates and (f) adsorption behavior of verapamil onto PS particles in methanol solution, in which PS was prepared in the presence of various volumes of styrene $(5-40 \mathrm{~mL})$ by fixing the amounts of BPO $(1.0 \mathrm{~g})$ and PVP $(1.0 \mathrm{~g})$ in $80 \mathrm{~mL}$ ethanol solution [note: the quantitative analysis was performed with paper spray mass spectrometry, and the desorption and adsorption performance of various PS particles were evaluated by the normalized peak intensity ratios between the characteristic fragment ion $\mathrm{m} / \mathrm{z} 303$ from protonated verapamil ( $\mathrm{m} / \mathrm{z} 455)$ and the characteristic fragment ion $\mathrm{m} /$ z 309 from the internal standard, protonated verapamil $(\mathrm{m} / \mathrm{z}$ 461) spiked in the samples; spray solvent or sample, $25 \mu \mathrm{L}$ methanol or adsorption solution; applied voltage, $3.5 \mathrm{kV}$ ].

of applied solvent at the surface of PS coated paper substrate (Fig. S2b $\dagger$ ) and immediate spray after applying high voltage. Quantitation of verapamil was achieved using the ratio of the fragment ion $(\mathrm{m} / \mathrm{z} 303)$ abundance from verapamil to that of the corresponding fragment ion $(\mathrm{m} / \mathrm{z} 309)$ generated from $\mathrm{D}_{6^{-}}$ verapamil (Fig. S3†). Fig. 1e shows the normalized concentration of detected verapamil from PS coated paper substrates, in which PS was prepared in the presence of differing volumes of styrene $(5-40 \mathrm{~mL})$ by fixing the amounts of BPO $(1.0 \mathrm{~g})$ and PVP $(1.0 \mathrm{~g})$ in $80 \mathrm{~mL}$ ethanol solution. Notably, the desorption behavior of verapamil demonstrates first an increasing trend followed by a decrease as the styrene volume in PS preparation 
increases. When the percentage of styrene was $23.4 \%$, namely $25 \mathrm{~mL}$ in volume, verapamil illustrated the most favorable desorption performance from PS particles. It should be pointed out that the on-line desorption experiment of verapamil from PS coated paper involved high voltage, paper substrate and an adhesive agent (soluble starch), but extensive investigation, in which the adsorption/desorption experiments were performed by eliminating these factors, demonstrated that they had little impact on the desorption performance (Fig. S4 $\dagger$ ). These results demonstrate that the on-line desorption experiments are not a result of the paper spray methodology.

The adsorption performance of these PS particles was carried out by mixing $0.2 \mathrm{~g}$ PS particles and $10 \mathrm{~mL}$ of methanol solution containing $1.0 \mu \mathrm{g} \mathrm{mL} \mathrm{mL}^{-1}$ verapamil followed by stirring for $30 \mathrm{~min}$. Afterwards, the upper clear solution was collected, separated and diluted with $\mathrm{D}_{6}$-verapamil solution. Fig. If exhibits the remaining content of verapamil in the adsorption solution as measured using paper spray mass spectrometry with uncoated filter paper. The error bars represent standard deviations from four replicate experiments. It is notable that with variation of styrene in the PS preparation, the detected amount of verapamil shows the opposite trend as that from the desorption experiments (Fig. 1e). When the volume of styrene was $25 \mathrm{~mL}$ in PS preparation, the generated product had the strongest adsorption capacity to verapamil. By comparing the desorption (Fig. 1e) and adsorption (Fig. 1f) behaviors of verapamil on the PS particles from various volumes of styrene, it is interesting that a stronger adsorption performance would lead to a more favorable desorption, which is contrary to the general view.

To demonstrate the generalization of the above phenomenon, a series of experiments with different parameters was carried out, which included various structures of molecules (e.g., amitriptyline, clozapine, quetiapine, risperidone and aripiprazole as shown in Fig. S5 $\dagger$ ), solvent systems (e.g., ethanol as Fig. S6, propanol as Fig. S7 and isopropanol as Fig. S8†), PS particles prepared through varying the amounts of PVP (Fig. S9a and $\mathrm{b} \dagger$ ), BPO (Fig. S9c and $\mathrm{d} \dagger$ ), $\mathrm{H}_{2} \mathrm{O}$ (Fig. S9e and $\mathrm{f} \dagger$ ) and styrene/BPO (Fig. S9g and $\mathrm{h} \dagger$ ) and from commercial sources with different particle sizes (Fig. S10 $\dagger$ ). The same results were observed for these experiments, indicating that the unique desorption and adsorption behaviors at PS surfaces were independent of molecular structure, solvent system and PS sources, and were a general phenomenon on PS surfaces. In contrast, when other materials, including different metal oxides (e.g., $\mathrm{TiO}_{2}, \mathrm{Al}_{2} \mathrm{O}_{3}, \mathrm{ZnO}, \mathrm{MgO}$ and $\mathrm{ZrO}_{2}$ as Fig. S11 $)$ and metalorganic frameworks [MOFs, e.g., MIL-53(Al), ZIP-8, and UiO$66(\mathrm{Zr})$ as Fig. $\mathrm{S} 12 \dagger]$, were employed, the opposite result was obtained. Specifically, a weaker adsorption would lead to a more favorable desorption behavior, in good agreement with the general adsorption-desorption view. These results suggest that the adsorption-desorption behavior of molecules on the PS surfaces is different from that on other materials, which might be attributable to the unique physicochemical properties of PS particles.

To gain an insight into the unique adsorption and desorption behaviors of PS particles, verapamil was used as a model compound and the adsorption kinetic processes were explored. As shown in Tables S1 and S2 and Fig. S13, $\dagger$ the adsorption process of verapamil on PS particles followed a pseudo-secondorder kinetic model and the Langmuir monolayer adsorption model. As shown in Fig. 2a, the initial adsorption of verapamil in the PS particles is quite fast followed by continued adsorption at a slower rate. Careful observation found that the adsorption rate exhibited a first increasing followed by decreasing with increase in the volume of styrene in PS preparation, and the PS from $25 \mathrm{~mL}$ styrene demonstrated the fastest adsorption rate to verapamil. As the prepared PS particles were coated on paper substrates for on-line desorption experiments, with increase in the elution number for the same paper substrate bearing a single sample spot, ${ }^{74}$ the desorption behavior of verapamil demonstrated a tendency (Fig. 2b) that is opposite that in the adsorption process (Fig. 2a), and the PS from $25 \mathrm{~mL}$ styrene gave the most favorable desorption behavior, in agreement with the desorption behavior of verapamil in conventional solution system (Fig. S14†). However, when the PS coated papers were used as substrates for thin layer chromatography of methylene blue, a reverse pattern was observed. Desorption from particulate surfaces (e.g., thin-layer chromatography experiments as Fig. S15, $\uparrow$ and the on-line as Fig. $1 \mathrm{a}$ and $2 \mathrm{~b}$ and the off-line desorption experiments as Fig. $\mathrm{S} 4 \mathrm{~b} \dagger$ ) takes place as adsorbate molecules overcome interaction energy with the surface (minus solvation energy) and are transferred from surface to solvent. Diffusion through the solvent limits the rate of desorption among particle surfaces. Taken these factors into account, it can be concluded that the former is realized through the transfer of solute molecules among PS particles, and the adsorption interactions between solutes and PS particles play a crucial role in determining the elution or desorption efficiency. For the latter, the desorption performance depends on not only the adsorption interactions between PS particles and solutes, but also the diffusion rate of solutes from solid surfaces to the bulk solution.

With variation in the preparation parameters, the surface structures (e.g., particle size and texture properties) and degree of polymerization of the PS particles generally have a great effect on their properties. ${ }^{67,68}$ However, no direct correlation was found between performance of the PS particles in
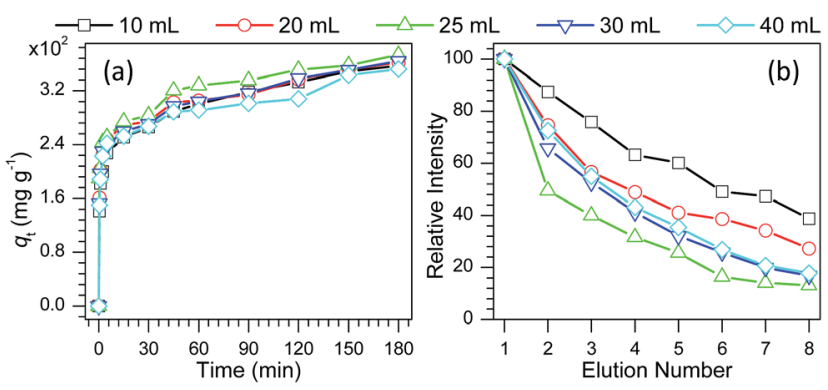

Fig. 2 (a) Time profiles of verapamil adsorption on PS particles in methanol solution containing $1.0 \mu \mathrm{g} \mathrm{mL}^{-1}$ verapamil and (b) elution curves of verapamil from PS coated paper substrates, in which PS was prepared by the reaction between various volumes of styrene (10-40 $\mathrm{mL}$ ) and $1.0 \mathrm{~g} \mathrm{BPO}$ and $1.0 \mathrm{~g}$ PVP in $80 \mathrm{~mL}$ ethanol. 
desorption and adsorption of pharmaceutical drugs and their particle sizes, texture properties and molecular weights (Tables S3 and S4 $\dagger$ ). Infrared spectrometry, as a powerful technique to characterize the surface properties of organic compounds, was also employed to study the surface properties of as-prepared PS particles. Fig. S16a † shows the typical FT-IR spectra of PS particles obtained by reaction of various volumes of styrene (10-40 mL) and $1.0 \mathrm{~g}$ BPO in the presence of $1.0 \mathrm{~g}$ PVP. Some absorption bands such as $1601 \mathrm{~cm}^{-1}$ and 1028 $\mathrm{cm}^{-1}$ (Fig. S16b†), demonstrated first a decreasing trend followed by increasing as the volume of styrene in preparation of PS particles increased. This trend mirrors the adsorption and desorption performance of the PS particles as discussed above (Fig. 1 and 2). Although the observed change is very small, these results provide a clue as to what causes the variation in desorption/adsorption capabilities of PS particles obtained from different preparation conditions. To confirm these changes, the PS particles, prepared by reaction of $25 \mathrm{~mL}$ styrene and $1.0 \mathrm{~g}$ BPO in the presence of $1.0 \mathrm{~g}$ PVP, were used as a model to adsorb different concentrations of verapamil (1.0-1000 $\left.\mu \mathrm{g} \mathrm{mL} \mathrm{m}^{-1}\right)$ in methanol solutions for $3 \mathrm{~h}$, respectively. As shown in Fig. S17, $\uparrow$ the above IR adsorption bands presented a gradually decreasing trend, suggesting that with increase in the adsorption amount of verapamil at the PS surfaces, it would have a more significant impact on the IR spectra of PS particles. Based on this fact, the IR spectra of the above PS particles obtained from different volumes of styrene (10-40 mL) were examined further after adsorption of verapamil in methanol solution containing $1000 \mu \mathrm{g} \mathrm{mL} \mathrm{L}^{-1}$ for $3 \mathrm{~h}$. Compared to the non-adsorbed PS particles (Fig. S16a $\dagger$ ), the IR spectra of adsorbed PS samples kept almost constant (Fig. 3a), and no obvious characteristic absorption bands of verapamil were observed (Fig. S18a $\dagger$ ) probably due to the small amount of verapamil adsorbed on PS particles (Fig. S18b $\dagger$ ). The major difference between those spectra is the intensity of the adsorption bands at 1720, 1601, 1400, 1271, 1028, 906, 756 and $540 \mathrm{~cm}^{-1}$. To demonstrate clearly their differences, transmittance difference ( $\Delta T$, Fig. $3 \mathrm{~b})$ was used to characterize the effect of styrene amount on the resulting PS particles. As shown in Fig. 3c, with varying the volume of styrene in PS preparation, the $\Delta T$ values present first a decreasing trend followed by increasing, in which the PS from $25 \mathrm{~mL}$ of styrene in preparation illustrates the lowest value for each case, in good agreement with the adsorption and desorption performances of the particles (Fig. 1 and 2). It should be mentioned here that when the volume of styrene is above than $25 \mathrm{~mL}$ in preparation, the surface properties of the obtained PS are also altered rather than maintaining constant. Detailed reasons are not clear and further investigation is still needed. For other PS samples, a similar phenomenon was also observed (Fig. S19$22 \dagger$ ). According to density functional theory (DFT) calculations, two types of intermolecular interactions (Fig. S23†), namely the $\mathrm{H}$ atom on the phenyl ring of PS and the $\mathrm{N}$ atom at the cyano group of verapamil ( $\mathrm{H}-\mathrm{N}$ hydrogen bond) and the $\mathrm{H}$ atoms on the phenyl ring of PS and the $\mathrm{O}$ atoms at the ether group of verapamil ( $\mathrm{H}-\mathrm{O}$ hydrogen bond), are mainly responsible for the adsorption of verapamil at PS surfaces.
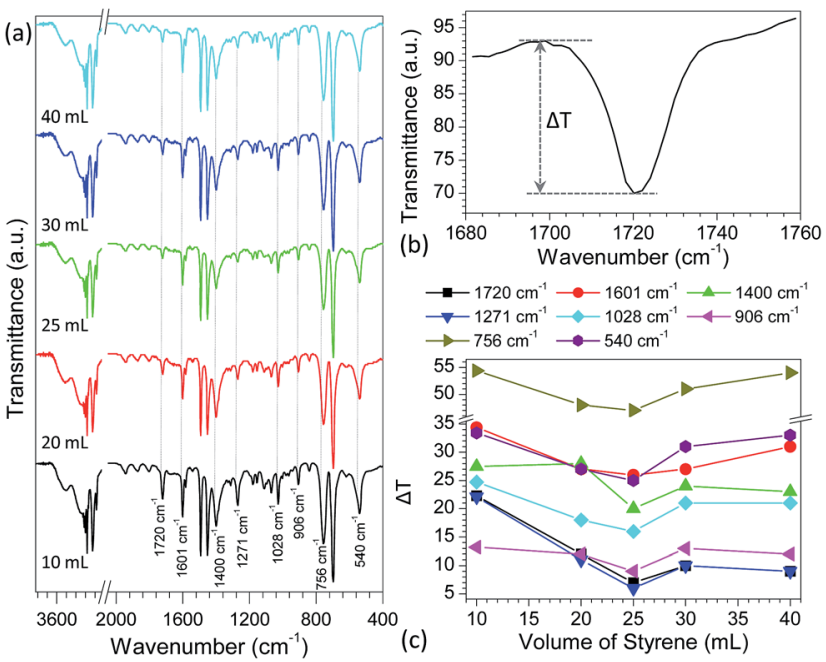

Fig. 3 (a) FT-IR spectra of PS particles after adsorption of verapamil in methanol solution containing $1000 \mu \mathrm{g} \mathrm{mL}^{-1}$ verapamil for $3 \mathrm{~h}$, in which the PS samples were prepared by reaction of various volumes of styrene $(10-40 \mathrm{~mL})$ and $1.0 \mathrm{~g} \mathrm{BPO}$ in the presence of $1.0 \mathrm{~g}$ PVP in 80 $\mathrm{mL}$ ethanol solution; (b) definition of transmittance difference $(\Delta T)$ using the characteristic absorption band at $1720 \mathrm{~cm}^{-1}$ as an example; (c) plots of the transmittance differences of different characteristic absorption bands with varying the volume of styrene in PS preparation.

As discussed above such as the bands at $1720 \mathrm{~cm}^{-1}$ (C-C stretching vibration for phenyl ring), $1271 \mathrm{~cm}^{-1}$ (C-C stretching vibration for the $\mathrm{CH}$ and $\mathrm{CH}_{2}$ groups directly attached to phenyl ring) and $540 \mathrm{~cm}^{-1}$ (C-C skeleton stretching vibration for phenyl ring), the $\mathrm{H}$ atoms on the phenyl ring of PS particles played a crucial role in determining the adsorption interactions of verapamil via hydrogen bond interactions and therefore, the characteristic IR bands of C-C skeleton stretching vibration either for phenyl ring or directly attached to phenyl ring in PS samples were greatly affected. With increase in the adsorption interaction of PS particles to verapamil, the IR bands changed significantly. As a result, the pattern of adsorption interaction for the PS particles, obtained by reaction of various volumes of styrene (10-40 mL) and $1.0 \mathrm{~g}$ BPO in the presence of $1.0 \mathrm{~g}$ PVP in $80 \mathrm{~mL}$ ethanol solution (Fig. 1 and 2), was proportional to the change in the band intensity of the above characteristic IR absorption (Fig. 3).

In conclusion, the combination of mass spectrometry with infrared spectrometry has demonstrated that a stronger adsorption interaction between PS particles and pharmaceutical drugs would lead to a more favorable desorption behavior. This observed phenomenon was independent of the source of PS particles, drug structure and used solvent, which was unique to PS in contrast to other materials such as metal oxides and MOFs. FT-IR results illustrated that the adsorption interaction of PS particles was related closely to the hydrogen bond interaction between studied drug and PS, and a weaker IR absorption band would result in a stronger adsorption interaction at PS surfaces. These results are expected to help us better understand the adsorption and desorption interaction between PS particles and target molecules. 


\section{Acknowledgements}

We thank Dr Milton Lee for helpful discussion and suggestions on the manuscript. This work was supported by the National Natural Science Foundation of China (21373112 and 21575112) and Shaanxi S\&T Research Development Project of China (No. 2014K13-16 and 2016GY-231).

\section{Notes and references}

1 J. Falkenhagen and S. Weidner, Anal. Chem., 2009, 81, 282287.

2 S. Saha, L. C. Chen, M. K. Mandal and K. Hiraoka, J. Am. Soc. Mass Spectrom., 2013, 24, 341-347.

3 S. Saha, M. K. Mandal, L. C. Chen, S. Ninomiya, Y. Shida and K. Hiraoka, Mass Spectrom., 2013, 2, S0008.

4 K. T. Rim, D. Eom, S.-W. Chan, M. Flytzani-Stephanopoulos, G. W. Flynn, X.-D. Wen and E. R. Batista, J. Am. Chem. Soc., 2012, 134, 18979-18985.

5 L. Qi, J.-P. Chapel, J.-C. Castaing, J. Fresnais and J.-F. Berret, Langmuir, 2007, 23, 11996-11998.

6 S. J. Jonas, A. Z. Stieg, W. Richardson, S. Guo, D. N. Powers, J. Wohlschlegel and B. Dunn, J. Phys. Chem. Lett., 2015, 6, 388-393.

7 O. León, E. Contreras, E. Rogel, G. Dambakli, J. Espidel and S. Acevedo, Energy Fuels, 2001, 15, 1028-1032.

8 B. P. Williams, S. Pinge, Y.-K. Kim, J. Kim and Y. L. Joo, Langmuir, 2015, 31, 8989-8997.

9 A. Dąbrowski, Adv. Colloid Interface Sci., 2001, 93, 135-224.

10 B. Mu and A. Wang, J. Environ. Chem. Eng., 2016, 4, 1274-1294.

11 L. Largitte and R. Pasquier, Chem. Eng. Res. Des., 2016, 109, 495-504.

12 K. Karimi and M. J. Taherzadeh, Bioresour. Technol., 2016, 203, 348-356.

13 S. Hokkanen, A. Bhatnagar and M. Sillanpää, Water Res., 2016, 91, 156-173.

14 K. Unger, Angew. Chem., Int. Ed., 1972, 11, 267-278.

15 I. Higuchi, T. Ree and H. Eyring, J. Am. Chem. Soc., 1957, 79, 1330-1337.

16 B. L. Harris, Ind. Eng. Chem., 1956, 48, 472-481.

17 A. B. Ray, Ind. Eng. Chem., 1947, 39, 12-13.

18 R. D. Tilton, C. R. Robertson and A. P. Gast, Langmuir, 1991, 7, 2710-2718.

19 B. D. Fair and A. M. Jamieson, J. Colloid Interface Sci., 1980, 77, 525-534.

20 C. Boisson-Vidal, J. Jozefonvicz and J. L. Brash, J. Biomed. Mater. Res., 1991, 25, 67-84.

21 W. Norde, F. G. Gonzalez and C. A. Haynes, Polym. Adv. Technol., 1995, 6, 518-525.

22 K. Jainae, K. Sanuwong, J. Nuangjamnong, N. Sukpirom and F. Unob, Chem. Eng. J., 2010, 160, 586-593.

23 J. Kluczka, T. Korolewicz, M. Zołotajkin and J. Adamek, Water Resources and Industry, 2015, 11, 46-57.

24 K. Xiao, F. Xu, L. Jiang, Z. Dan and N. Duan, Chemosphere, 2016, 156, 326-333.

25 N. Chaukura, B. B. Mamba and S. B. Mishra, J. Environ. Manage., 2017, 193, 280-289.
26 B. Emo, C. T. Eberlin, K. R. Hixon, E. A. Growney Kalaf, J. M. Laktas and S. A. Sell, J. Environ. Chem. Eng., 2017, 5, 232-239.

27 J. C. Masini, J. Sep. Sci., 2016, 39, 1648-1655.

28 J.-B. Qu, G.-S. Huan, Y.-L. Chen, W.-Q. Zhou, J.-G. Liu and F. Huang, ACS Appl. Mater. Interfaces, 2014, 6, 12752-12760.

29 X. Cao, Q. Kong, R. Cai, K. Zhu, X. Ye, J. Chen, W. Mo and J. Wang, J. Sep. Sci., 2014, 37, 3677-3683.

30 X. Huang, S. Zhang, G. A. Schultz and J. Henion, Anal. Chem., 2002, 74, 2336-2344.

31 D. Sacco and E. Dellacherie, Anal. Chem., 1984, 56, 15211524.

32 Z. Iskandarani and D. J. Pietrzyk, Anal. Chem., 1982, 54, 2427-2431.

33 S. Mori, Anal. Chem., 1978, 50, 745-748.

34 M. E. León-González and L. V. Pérez-Arribas, J. Chromatogr. A, 2000, 902, 3-16.

35 H. W. Kauczor and A. Meyer, Hydrometallurgy, 1978, 3, 65-73. 36 V. V. Tolmacheva, V. V. Apyari, A. A. Furletov, S. G. Dmitrienko and Y. A. Zolotov, Talanta, 2016, 152, 203-210.

37 M. Trautmann, S. Lubahn and H.-J. Holdt, React. Funct. Polym., 2014, 83, 84-97.

38 W. W. Yang, G. S. Luo and X. C. Gong, Sep. Purif. Technol., 2005, 43, 175-182.

39 T. Saitoh, S. Suzuki and M. Hiraide, J. Chromatogr. A, 2005, 1097, 179-182.

40 S. Jara, C. Lysebo, T. Greibrokk and E. Lundanes, Anal. Chim. Acta, 2000, 407, 165-171.

41 K. Sofińska, Z. Adamczyk and J. Barbasz, Colloids Surf., B, 2016, 137, 183-190.

42 A. Vesel and K. Elersic, Appl. Surf. Sci., 2012, 258, 5558-5560.

43 R. Jain and D. Forciniti, Langmuir, 2012, 28, 15323-15335.

44 M. M. Browne, G. V. Lubarsky, M. R. Davidson and R. H. Bradley, Surf. Sci., 2004, 553, 155-167.

45 J. Wang, S. M. Buck, M. A. Even and Z. Chen, J. Am. Chem. Soc., 2002, 124, 13302-13305.

46 J. Wang, X. Chen, M. L. Clarke and Z. Chen, J. Phys. Chem. B, 2006, 110, 5017-5024.

47 J. R. Long, N. Oyler, G. P. Drobny and P. S. Stayton, J. Am. Chem. Soc., 2002, 124, 6297-6303.

48 K. Aoki and Y. Adachi, J. Colloid Interface Sci., 2006, 300, 6977.

49 M. G. Kontominas, R. Gavara and J. R. Giacin, Eur. Polym. J., 1994, 30, 271-277.

50 S. Sakai, J. Kim, B. Hexig, Y. Okahata, C. S. Cho and T. Akaike, Colloids Surf., B, 2012, 94, 192-198.

51 H. M. Eckenrode and H.-L. Dai, Langmuir, 2004, 20, 92029209.

52 M. J. Pollitt, G. Buckton, S. Brocchini and H. O. Alpar, Int. J. Pharm., 2005, 298, 333-338.

53 S. F. Turner, S. M. Clarke, A. R. Rennie, P. N. Thirtle, Z. X. Li, R. K. Thomas, S. Langridge and J. Penfold, Langmuir, 2005, 21, 10082-10088.

54 T. Hanai and J. Hubert, Chromatographia, 1983, 17, 633-639. 55 M. Martinez, A. Carrancio, J. L. Casillas and J. Aracil, Ind. Eng. Chem. Res., 1995, 34, 4486-4493. 
56 R. V. Snyder, R. J. Angelici and R. B. Meck, J. Am. Chem. Soc., 1972, 94, 2660-2663.

57 C. S. Su and D. Patterson, Macromolecules, 1977, 10, 708-710.

58 R. H. Schuster, H. Graeter and H. J. Cantow, Macromolecules, 1984, 17, 619-625.

59 B. M. Van Liedekerke, H. J. Nelis, W. E. Lambert and A. P. De Leenheer, Anal. Chem., 1989, 61, 728-732.

60 Q. B. Meng, G.-S. Yang and Y.-S. Lee, Microporous Mesoporous Mater., 2013, 181, 222-227.

61 M. S. Romero-Cano, A. Martín-Rodríguez and F. J. de las Nieves, J. Colloid Interface Sci., 2000, 227, 329-333.

62 M. S. Romero-Cano, A. Martín-Rodríguez and F. J. de las Nieves, J. Colloid Interface Sci., 2000, 227, 322-328.

63 A. Nieto, A. Gayá, C. Moreno, M. Jansá and J. Vives, Ann. Inst. Pasteur/Immunol., 1986, 137, 161-172.

64 R. A. Lauten, A.-L. Kjøniksen and B. Nyström, Langmuir, 1984, 16, 4478-4484.

65 X. Wang, Y. Zheng, T. Wang, X. Xiong, X. Fang and Z. Zhang, Anal. Methods, 2016, 8, 8004-8014.
66 M. Schulz, S. Iwersen-Bergmann, H. Andresen and A. Schmoldt, Crit. Care, 2012, 16, R136.

67 A. J. Paine, W. Luymes and J. McNulty, Macromolecules, 1990, 23, 3104-3109.

68 S. T. Ha, O. O. Park and S. H. Im, Macromol. Res., 2010, 18, 935-943.

69 H. Wang, J. Liu, R. G. Cooks and Z. Ouyang, Angew. Chem., Int. Ed., 2010, 49, 877-880.

70 Z. Pei, L. Busenlehner, S. D. Worley, Y. Tang and C. W. Curtis, J. Phys. Chem. B, 1997, 101, 10450-10454.

71 F. J. Torres, B. Civalleri, C. Pisani, P. Musto, A. R. Albunia and G. Guerra, J. Phys. Chem. B, 2007, 111, 6327-6335.

72 Y. Zheng, X. Zhang, H. Yang, X. Liu, X. Zhang, Q. Wang and Z. Zhang, Anal. Methods, 2015, 7, 5381-5386.

73 Y. Zheng, Q. Wang, X. Wang, Y. Chen, X. Wang, X. Zhang, Z. Bai, X. Han and Z. Zhang, Anal. Chem., 2016, 88, 70057013.

74 Z. Zhang, W. Xu, N. E. Manicke, R. G. Cooks and Z. Ouyang, Anal. Chem., 2012, 84, 931-938. 